\title{
Joint processing of RS and WWLLN data for forest fire danger estimation: new concept

\author{
Nikolay V. Baranovskiy ${ }^{1 *}$, Svetlana Yu. Krechetova ${ }^{2}$, Marina Yu. Belikova ${ }^{2}$, Nina A. Kocheeva ${ }^{2}$, \\ Elena P. Yankovich ${ }^{1}$ \\ ${ }^{1}$ National Research Tomsk Polytechnic University, Tomsk, Russia, 634050 \\ ${ }^{2}$ Gorno-Altaisk State University, Gorno-Altaisk, Russia, 649000
}

\begin{abstract}
The present article describes a new concept of lightning-caused forest fire danger using a probabilistic criterion. The assessment of forest fire danger is made on the basis of the algorithm that classifies the forest territory by vegetation conditions. Lightning activity is processed by the MODIS spectroradiometer according to the World Wide Lightning Location Network data and remote sensing data for the Timiryazevskiy forestry in the Tomsk Region. The cluster analysis of the WWLLN and MOD06_L2 product data are used in the present paper.
\end{abstract}

Keywords: forest fire danger, prediction, lightning activity, remote sensing, WWLLN, GIS

\section{Introduction}

The modern scientific community is actively engaged in the research in the field of forest fires. A number of researchers are engaged in evaluating the conditions of a forest fire front spreading [1] to be able to assess the opportunities for its location or to adopt the security measures in a nearby village [2]. Other scientists are looking for the ways to extinguish a forest fire effectively [3]. Any fire incident starts with a surface fire [4]. Therefore, it seems appropriate to develop the methods, approaches, and technologies of forest fire danger anticipation [5]. The development of methods to assess, monitor, and forecast forest fires takes an important role in solving this problem [6]. The assessment requires the information about the current state of a forest fire season [7]. The monitoring is carried out to collect the current and retrospective information to predict the future forest fire danger [8]. The forecast may be shortterm, medium-term, and long-term [9]. The causes of forest fires, in their turn, are human-induced or of natural character [10]. The forest fire under thunderstorm activity conditions is the most noteworthy issue [11]. There are different approaches to solve the problem to estimate and forecast the forest fire danger caused by thunderstorms [12-15]. Nevertheless, all of these methods and approaches are without a physical basis [16].

The geographic information system to forecast the forest fire danger caused by thunderstorms is currently being developed using a deterministic and probabilistic approach [17]. The probabilistic assessment of a forest fire danger scenario is used [18], and the process development in each scenario is described by a deterministic mathematical model [19]. The information about the lightning processes in the controlled forest area is needed to monitor and forecast the forest fire danger caused by thunderstorm activity. The global WWLLN network is currently operating in the world [20]. Its data can be used to analyse thunderstorm activity in the particular region.

The study aim is to formulate a new concept to assess, monitor, and forecast the forest fire danger under thunderstorm activity conditions using the data of:

- the Earth surface satellite remote sensing,

- the surface layer of the atmosphere,

- the WWLLN lightning direction finding network .

\section{Lightning-caused forest fire danger prediction model}

A probabilistic criterion formula to assess the forest fire danger caused by thunderstorms has been developed. The spatiotemporal dynamics of thunderstorm activity is taken into account. Firstly, the probabilistic criterion considers the level of thunderstorm activity in the controlled forest area on the basis of the retrospective thunderstorm front forming within the specified territory [21]. Secondly, the criterion also takes into account a cloud-to-ground lightning discharge especially that occurs during the night and can lead to the secondary forest fires.

*firedanger@narod.ru, phone+7-903-953-56-95, tpu.ru

Remote Sensing of Clouds and the Atmosphere XXI, edited by Adolfo Comerón, Evgueni I. Kassianov,

Klaus Schäfer, James W. Jack, Richard H. Picard, Konradin Weber, Proc. of SPIE Vol. 10001,

$1000113 \cdot$ (c) 2016 SPIE · CCC code: 0277-786X/16/\$18 - doi: 10.1117/12.2241853 
The formula to estimate the forest fire probability caused by lightning activity is the following:

$$
P_{L}=P(L) P\left(L / L_{j}\right) P\left(F F / L / L_{j}\right) P(D),
$$

where $\mathrm{P}_{\mathrm{L}}$ is the probability of a forest fire caused by thunderstorm, $\mathrm{P}(\mathrm{L})$ is the probability of a thunderstorm, $\mathrm{P}$ $(\mathrm{L} / \mathrm{Lj})$ is the probability of a cloud-to-ground lightning discharge while a thunderstorm front is passing, $\mathrm{P}(\mathrm{FF} / \mathrm{L} / \mathrm{Lj})$ is the probability of forest fuel ignition, $\mathrm{P}(\mathrm{D})$ is the probability that a forest fuel is dry.

The maturity of a forest fuel occurs first. Then a forest fire may break out provided that the storm front has formed in the territory. It is also necessary to take into account the probability of a cloud-to-ground lightning discharge [22].

\section{Forest taxation data}

The forest taxation characteristic has great value for the correct assessment of forest fire danger. There is a group of forest areas that are divided into district forestries according to the forestry organization in the Russian Federation. The blocks are allocated in each district forestry, they consist of homogeneous inventory areas. The algorithm classifying the forest inventory areas and evaluating the fire danger of blocks on site has been previously developed [23]. Quite a simple assessment of the forest fire danger on site can base on the formula relating the number of fire hazardous inventory areas to the total number of inventory areas in the controlled area.

This information can be visualized in a separate layer of the geographic information system. A software tool has been developed using the high-level Python programming language to classify the inventory areas and evaluate the fire hazard of a block in the geographic information system. It is a built-in tool to develop additional modules [24].



Figure 1. Raster image of Timiryazevskiy forestry in GIS

\section{WWLLN Data and Remote Sensing Analysis: Case Study}

There was a thunderstorm without precipitation according to the Tomsk weather station data in its vicinity in some hours on the $22^{\text {nd }}$ of July, 2014 (reliable prognosis rp5.ru). The thunderstorm began at $13.00 \mathrm{pm}$. The approximate time of the thunderstorm beginning and end has been determined using the information about lightning discharges obtained 
from the WWLLN network for the given date. The dynamics of thunderstorm cells (clusters) has been studied during its passage as well. Figure 1 shows the spatial distribution of the obtained clusters of lightning discharges according to input conditions 20,3,20. The cluster numbers correspond to the sequence of their occurrence. According to the WWLLN data the thunderstorm started at $13.27 \mathrm{pm}$ local time and ended at $21.41 \mathrm{pm}$ local time that day. Cluster 54, which had been operating for about 3.5 hours and had 267 bits, was the greatest in duration and the number of bits. The activity of clusters 48,51 , and 52 had been noted for 40 minutes. The lifetime of other clusters was about 10 minutes.

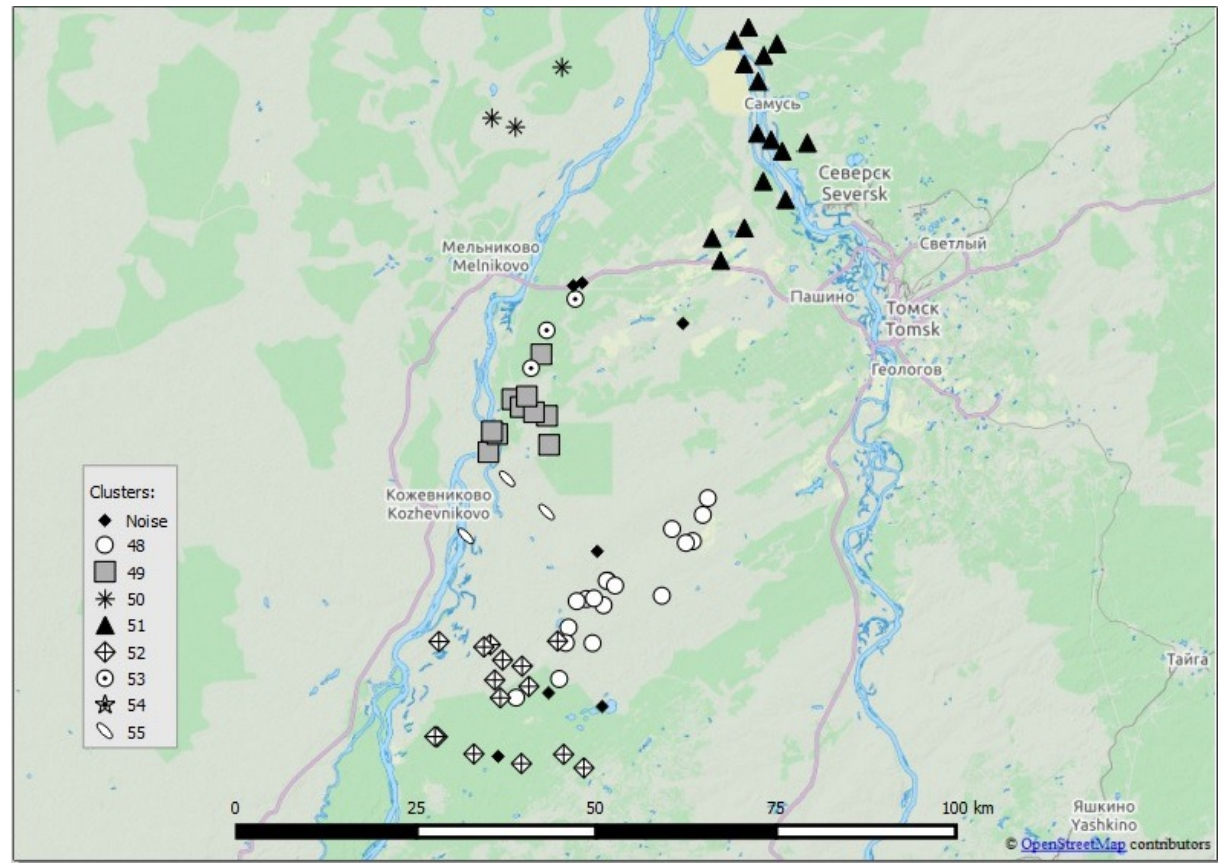

a)

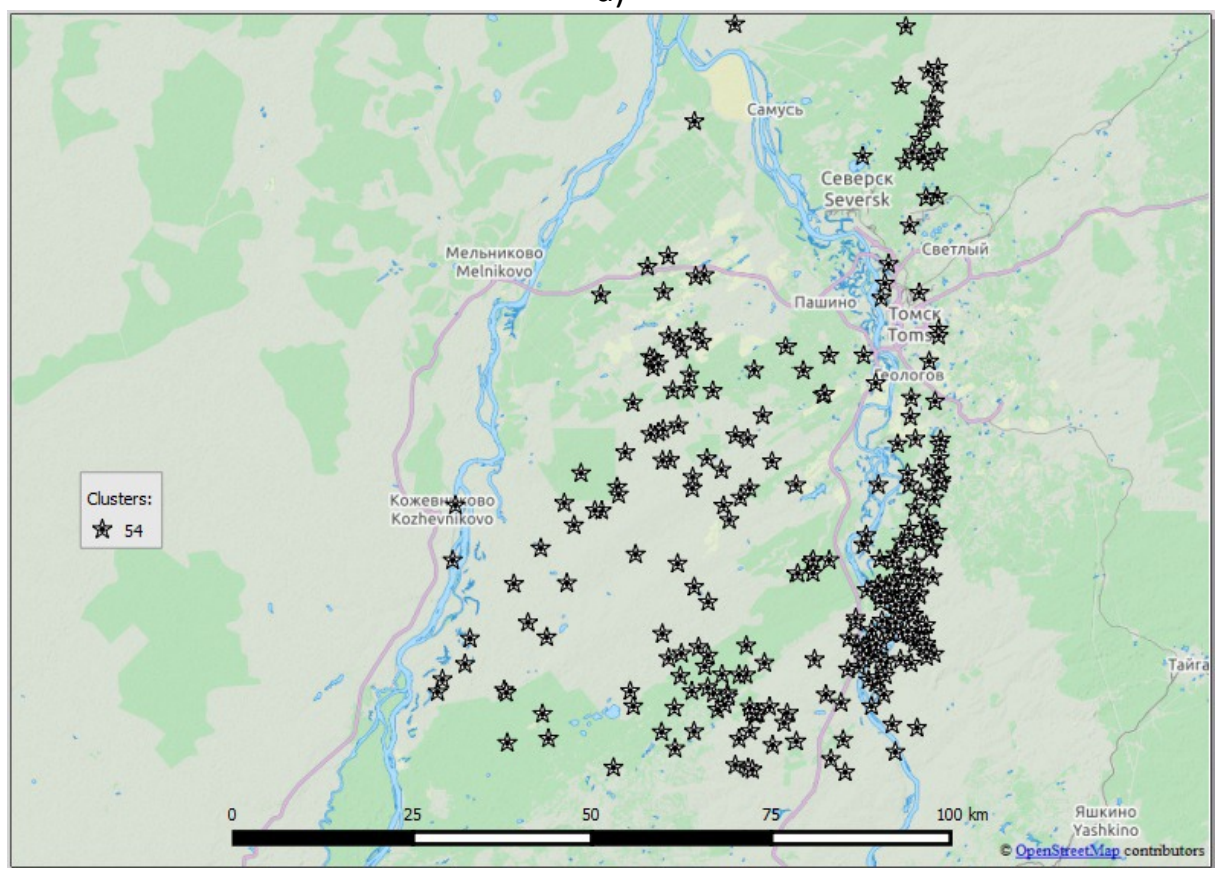

b)

Figure 2 - Clusters lightning obtained for the input parameters 20, 3, 20: a - Repose clusters without cluster at No. 54 ; b - representation of the cluster 54 
The WWLLN thunderstorm clusters have been compared with the weather stations data and satellite data on cloud parameters. The data of the MODIS sensor on the Terra platform and its product MOD06_L2, which combines infrared and visible techniques to determine both physical and radiative cloud properties, have been used to compare the lightning data with the WWLLN clusters [http://modis-atmos.gsfc.nasa.gov/_docs/MOD06- ATBD_2015_05_01.pdf]. We have considered the MOD06_L2 data before and during the thunderstorm on the $22^{\text {nd }}$ of July 2014 (Fig. 3 ).

Figure 3 shows the lightning discharges from $13.35 \mathrm{pm}$ to $13.55 \mathrm{pm}$ that belong to cluster 48 . The whole area of the thunderstorm cluster corresponds to the area of low temperature cloud tops and area in the clouds containing ice particles. Nevertheless, we should note that these areas exceed the thunderstorm areas in quantity. On the one hand, this is due to the errors in the algorithms of cloud microphysical parameters recovery according to the MODIS data [25]. On the other hand, the development of cloud lightning activity has not yet been fully studied and may have additional parameters that we can not consider in this case.
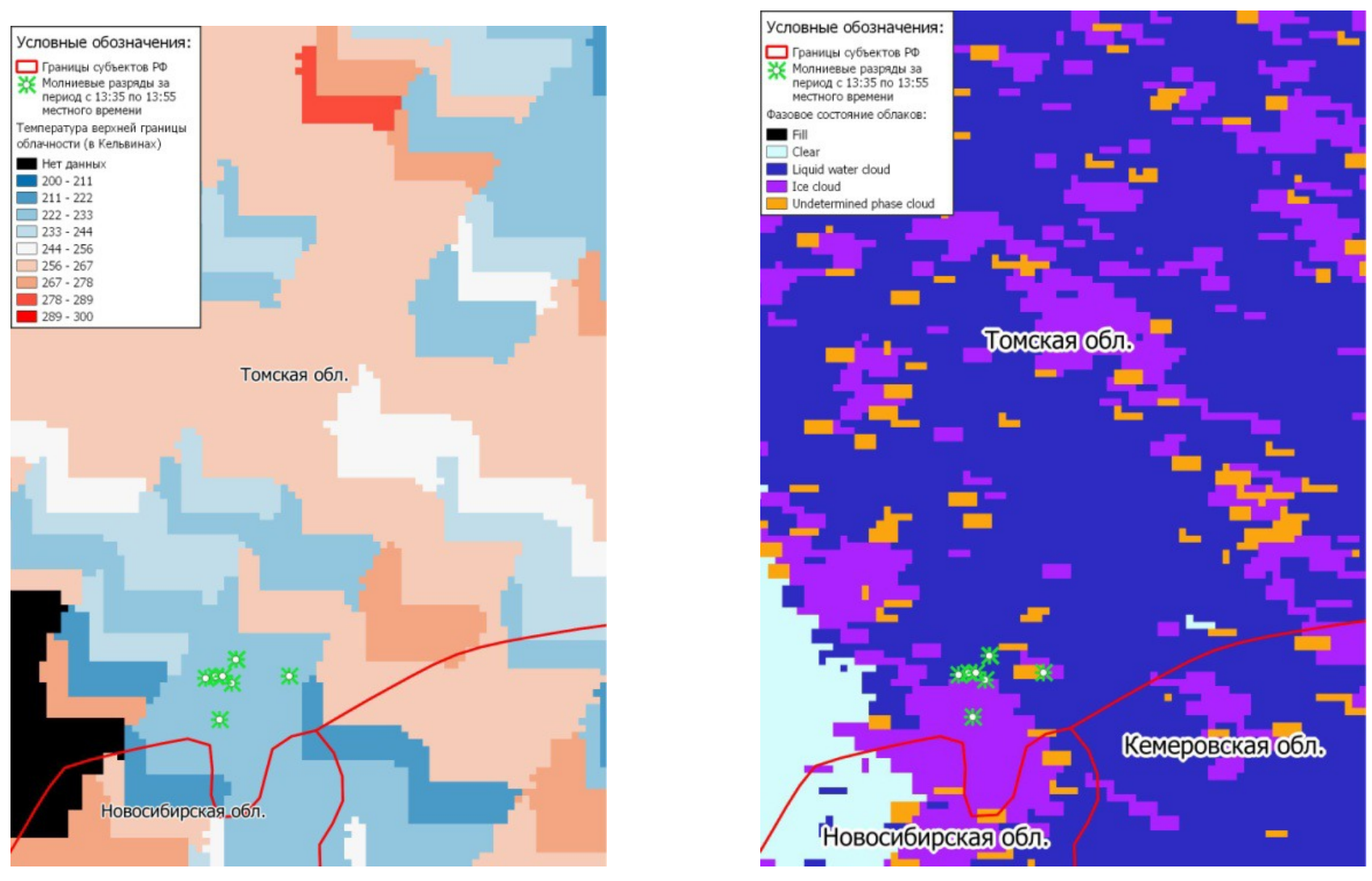

Figure 3 - Cloud parameters according to MOD06_L2 before (12.10 pm local time) and at beginning of thunderstorm (13.45 pm local time), 22 July, 2014, Tomsk Region: a) temperature of cloud tops (K); b) phase state of clouds (water, ice, undefined)

\section{Conclusion}

This article presents the new concept to assess the forest fire danger caused by lightning activity. Within the scope of this initiative the deterministic and probabilistic method to estimate the forest fire danger, satellite data, and the WWLLN global lightning network data are integrated. The analysis of thunderstorm activity has been carried out in the Tomsk Region (the Timiryazevskiy forestry) using both technologies. The prospects of these technologies joint use have been proved to monitor and forecast the forest fires caused by thunderstorms. 


\section{Acknowledgements}

This research implemented with financial support by Russian Foundation for Basic Research and Tomsk region administration. Grant 16-41-700831.

The authors wish to thank the World Wide Lightning Location Network (http://wwlln.net), a collaboration among over 50 universities and institutions, for providing the lightning location data used in this paper.

\section{References}

[1] Muzy A., Nutaro J.J., Zeigler B.P., Coquillardd P., "Modeling and simulation of fire spreading through the activity tracking paradigm", Ecological modeling, 219, 212 - 225 (2008)

[2] Modugno S., Balzter H., Cole B., Borrelli P., "Mapping regional patterns of large forest fires in Wildland-Urban Interface areas in Europe", Journal of Environmental Management, 172, 112 - 126 (2016)

[3] Volkov R.S., Kuznetsov G.V., Strizhak P.A., "Experimental investigation of mixtures and foreign inclusions in water droplets influence on integral characteristics of their evaporation during motion through high-temperature gas area", International Journal of Thermal Sciences, 88, 193 - 200 (2015)

[4] Baranovskiy N.V., Zakharevich A.V., "Experimental investigation of processes of typical forest fuel ignition by a high-temperature steel particle", Heat Transfer Research, 47, 681 - 689 (2016)

[5] Parente J., Pereira M.J., Tonini M., "Space-time clustering analysis of wildfires: The influence of dataset characteristics, fire prevention policy decisions, weather and climate", Science of the Total Environment, 559, $151-165$ (2016).

[6] Aslan Y.E., Korpeoglu I., Ulusoy O., "A framework for use of wireless sensor networks in forest fire detection and monitoring", Computers, Environment and Urban Systems, 36, 614 - 625 (2012)

[7] Eskandari S., Chuvieco E., "Fire danger assessment in Iran based on geospatial information", International Journal of Applied Earth Observation and Geoinformation, 42, 57 - 64 (2015)

[8] Sakr G.E., Elhajj I.H., Mitri G., "Efficient forest fire occurrence prediction for developing countries using two weather parameters", Engineering Applications of Artificial Intelligence, 24, 888 - 894 (2011)

[9] Baranovskiy N.V., "Project of eurasian segment of the new system of forest fire risk prediction based on information and computer technologies", Journal of Automation and Information Sciences, 47(3), 40 - 56 (2015)

[10] Hu T., Zhou G., "Drivers of lightning- and human-caused fire regimes in the Great Xing'an Mountains", Forest Ecology and Management, 329, 49 - 58 (2014).

[11] Vecín-Arias D., Castedo-Dorado F., Ordónez C., Rodríguez-Pérez J.R., "Biophysical and lightning characteristics drive lightning-induced fire occurrence in the central plateau of the Iberian Peninsula", Agricultural and Forest Meteorology, 225, 36 - 47 (2016)

[12] Mölders N., "Comparison of Canadian Forest Fire Danger Rating System and National Fire Danger Rating System fire indices derived from Weather Research and Forecasting (WRF) model data for the June 2005 Interior Alaska wildfires", Atmospheric Research, 95, 290 - 306 (2010)

[13] Grishin A.M., Filkov A.I., "A deterministic-probabilistic system for predicting forest fire hazard", Fire Safety Journal, 46, 56 - 62 (2011)

[14] Dissing D., Verbyla D.L., "Spatial patterns of lightning strikes in interior Alaska and their relations to elevation and vegetation", Canadian Journal of Forest Research, 33, 770 - 782 (2003)

[15] Chuvieco E., Aguado I., Yebra M., Nieto H., Salas J., Martína MP, Vilar L., Martínez J., Martín S., Ibarra P., de la Riva J., Baeza J. , Rodríguez F., Molina JR, Herrera MA, Zamora R., "Development of a framework for fire risk assessment using remote sensing and geographic information system technologies", Ecological Modelling, 221, 46 - 58 (2010)

[16] Kuznetsov G.V., Baranovskiy N.V. [Forecast of forest fire occurrence and their ecological consequences]. Publishing house of the Siberian Branch of the Russian Academy of Science, Novosibirsk. 301 P. (2009) (In Russian)

[17] Baranovskiy N.V. [Mathematical modeling of the most probable scenarios and conditions of forest fires]. Tomsk: TSU, 153 P. (2007) (In Russian)

[18] Baranovskiy N.V., "Assessment of the likelihood of forest fires, taking into account the meteorological conditions, anthropogenic load and thunderstorm activity", Fire Safety, 1, 93 - 99 (2009) (In Russian) 
[19] Kuznetsov G.V., Baranovskiy N.V., Barakhnin V.B., "Mathematical simulation of heat transfer at deciduous tree ignition by cloud-to-ground lightning discharge", EPJ Web of Conferences, 82, 1-6, Paper 01019 (2015)

[20] Jacobson A.R., Holzworth R.H., Harlin J., Dowden R.L., Lay E.H., "Performance assessment of the World Wide Lightning Location Network (WWLLN), using the Los Alamos Sferic Array (LASA) array as ground-truth", Journal of Atmospheric and Oceanic Technology, 23, 1082 - 1092 (2006)

[21] Gorbatenko V.P., Krechetova S.Y., Belikova M.Y., Nechepurenko O.E., "The comparison of atmospheric instability indices retrieved from the data of radio sounding and MODIS spectroradiometer on thunderstorm days over West Siberia", Russian Meteorology and Hydrology, 40, 289 - 295 (2015)

[22] Tsunomura S., Nishihashi M., Kusunoki K., "Electrical charge associated with cloud-to-ground lightning discharge in the Shonai area, Tohoku district, Japan", Papers in Meteorology and Geophysics, 66, 25 - 37 (2016)

[23] Yankovich E.P., Baranovskiy N.V., "Forest taxation data geoprocessing for assessment of forest fire danger caused by focused sunlight", International Multidisciplinary Scientific GeoConference Surveying Geology and Mining Ecology Management, SGEM, 1(2), 607 - 612 (2014)

[24] Baranovskiy N.V., Yankovich E.P., "Geoinformation monitoring of forest fire danger on the basis of remote sensing data of surface by the artificial earth satellite", Journal of Automation and Information Sciences, 47(8), 11 - 23 (2015)

[25] Li Z., Cribb M.C., Chang F.-L., Trishchenko A.P., "Validation of MODIS-Retrieved Cloud Fractions Using Whole Sky Imager Measurements at the Three ARM Sites", Fourteenth ARM Science Team Meeting Proceedings, Albuquerque, New Mexico, March 22-26, 1 - 6 (2004) 